$\xi=-1$

\title{
Development and Characterization on sound acoustic at photo- induced polymer foam composited at prolonged ultra-violet exposure
}

\author{
M. Taufiq Zaliran, Anika Zafiah M. Rus*, Shaharuddin Kormin, M Shafiq M Azahari \\ Sustainable Polymer Engineering, Advanced Manufacturing and Material Center (SPEN-AMMC), Faculty of Mechanical and Manufac- \\ turing Engineering (FKMP), Universiti Tun Hussein Onn Malaysia (UTHM), 86400 Parit Raja, Batu Pahat, Johor, Malaysia \\ *Corresponding author E-mail: zafiah@uthm.edu.my
}

\begin{abstract}
In this paper, polymer foam composites (FC) have been developed based on polyol mixed flexible crosslinker and fibre filler of Meranti Merah. $10 \mathrm{~mm}, 20 \mathrm{~mm}$ and $30 \mathrm{~mm}$ thickness of foam polymer and its composites have been use in this study. The percentage loading of wood fibre of $5 \%, 10 \%, 15 \%$ and $20 \%$ added with polymer foam is namely as polymer foam $\left(\mathrm{P}_{\mathrm{P}}\right)$ and its composites of $\mathrm{P}_{\mathrm{P} 5}, \mathrm{P}_{\mathrm{P} 10}$, $\mathrm{P}_{\mathrm{P} 15}$ and P 20 . The sound absorption coefficient $(\alpha)$ and pore structure of the foam samples have been measure by using Impedance Tube test and Scanning Electron Microscopy (SEM). UV Weatherometer is used to examine the durability and weatherproof of its composite. The results show that the highest thickness of the highest percentage fiber filler $\left(\mathrm{P}_{\mathrm{p} 2030)}\right.$ gives higher sound absorption coefficient $(\alpha) .0 .9922$ and 0.99889 which contributed from low and high frequency absorption level respectively. The smallest pores size structure was observed with highest filler loading of $\mathrm{P}_{\mathrm{P} 20}$. The higher the thickness and the higher the percentage loading of wood filler gives smaller pore structure, consequently, increased the sound absorption coefficient level. Meanwhile, the stability of polymer foam composites is high due to unchanged pore structures morphology with prolonged ultra violet exposure.
\end{abstract}

Keywords: Polymer foam composites; sound absorption coefficient; wood filler.

\section{Introduction}

As the consequence of undesirable and potentially insecure noise has become serious, the demand of fitter environment and residential safety is expanding and becomes one of the vital requirements. Various studies focusing acoustic properties have been performed. Based on acoustical material which works importantly in sound engineering for example aeronautic noise, heavy industrial and automotive noise [1].

Based on past study, polyurethane foams composites generated from waste cooking oil with the stabilizer filler such as titanium dioxide [2]. The composite synthesized, crosslink and synthetic powder as a filler of polyurethane foam [3-4]. Recently, study probe and employ assorted capability of being renewable resources and low-cost waste cooking oils, which role as a have potential by applied chemistry [4].

In this study, polymer foam composites (FC) were developed according to of epoxy with isocyanate and fiber filler. In this work, sawmill and furniture industry into a new invention or reuse to produce a worth product by their excessive from the process of the mill. This practice will require less energy, diminishes pollutants and reduced cost.

The concept sustainability of manufacturing technology is our quantification of the ability to get use of the manufacturing industry by the current days in illustrating the environmental friendly systems and processes productions for the upcoming generation. Meranti Merah wood being used due of its immoderate sources. The sound absorption coefficient of the polymer foam its composites were determined to study the affected of adding fiber as a filler in sample. Meranti Merah fiber is choose caused of their obtainability. Fiber from sawdust is lignocellulosic by product from sawmill industry. Nowadays, manufacturing industry of sawmill industry have increased. The wasting from this industry is eventually will be dispose of through burning that will cause pollution. Thus, recycling the wood waste as way polymer foam is one possible to be use and fabricated into useful product of sound absorption material.

By mixed two different material will produce new material that give good opportunity in sound absorption material. Other measure and analyze the sound absorption from different thickness of polymer foam composite and to investigate the durability of foam after UV irradiation.

\section{Materials and Methods}

\subsection{Preparation of foam composite}

One shot method used to making sample. The pre-determined all ingredient were mixed to making polymer foam and its composites. Firstly, the polyol were pour in the plastic container approximately 3.0 gram, followed by wood filler, with $5 \%, 10 \%, 15 \%$ or $20 \%$ of epoxy weight ratio. The crosslinker were mix together and vigorous stirred and placed to cure at room temperature.

The polymer foam composite is making by mix together the epoxy and crosslinker at a ratio of 1:0.5 respectively. The will allow an exothermic polymerization reaction. 
The mixture were left to cure to occur for 24 hour at room tem 'mold that called ad Teflon with a diameter of $100 \mathrm{~mm}$ and 28 $\mathrm{mm}$. Table 1 shows the naming of specimen

Table 1: The proportion ratio of polymer foam composite

\begin{tabular}{|c|c|c|c|}
\hline & & \multicolumn{2}{|c|}{ Percentage Loading } \\
\hline Sample & Epoxy $(\mathrm{g})$ & Crosslinker $(\mathrm{g})$ & Woods Filler $(\%)$ \\
\hline $\mathrm{P}$ & 30 & 15 & 0 \\
\hline $\mathrm{P}_{\mathrm{P} 5}$ & 30 & 15 & 5 \\
\hline $\mathrm{P}_{\mathrm{P} 1}$ & 30 & 15 & 10 \\
$\mathrm{P}_{\mathrm{P} 10}$ & & & 15 \\
\hline $\mathrm{P}_{\mathrm{P} 15}$ & 30 & 15 & 9 \\
$\mathrm{P}_{\mathrm{P} 15}$ & & 15 & \\
\hline $\mathrm{P}_{\mathrm{P} 20}$ & 30 & & \\
$\mathrm{P}_{\mathrm{P} 20}$ & & & \\
\hline
\end{tabular}

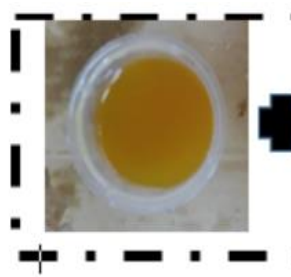

Crosslinke

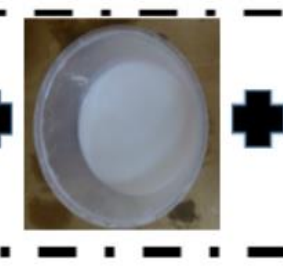

Polyol

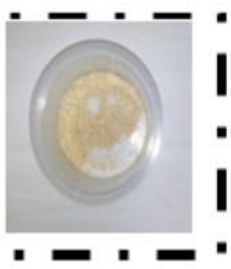

Woods filler
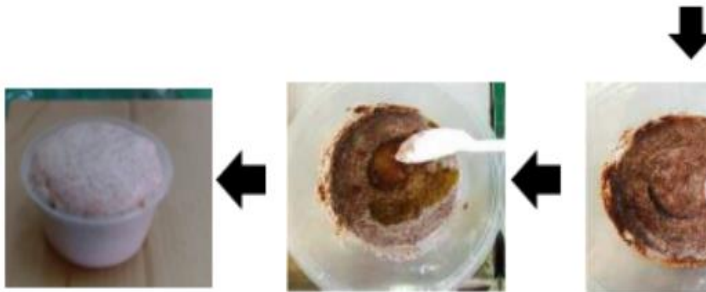

Stirring
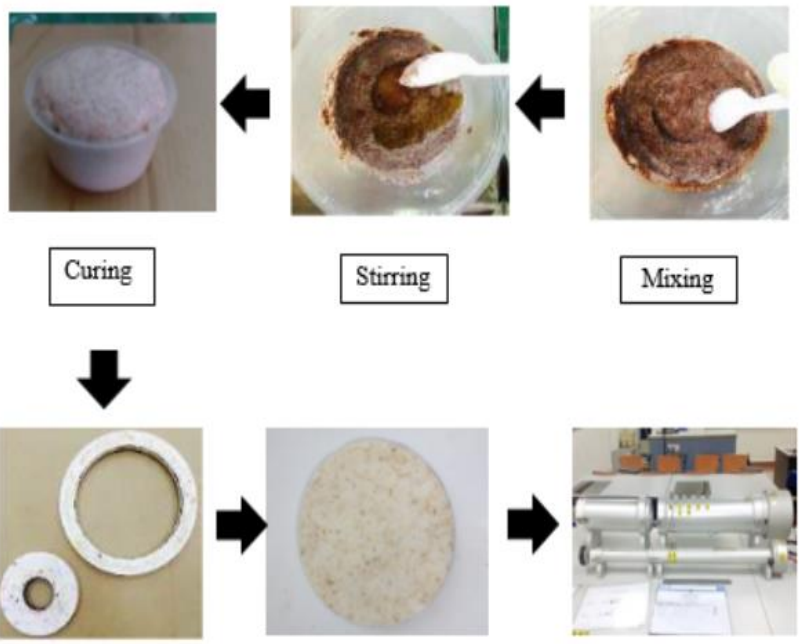

\section{Teflon Mould}

Foam

Impedance tube test

Fig. 1: The schematic diagram of polymer foam composites fabrication production.

\subsection{Sound absorption characteristics of $P U$ composites using impedance tube test}

The sound absorption were measure experimental using the impedance tube, it consists of an variable filter, propagation tube, large sample tube of $100 \mathrm{~mm}$ diameter for low frequency ( 0 to $1500 \mathrm{~Hz}$ ), small sample tube of $28 \mathrm{~mm}$ diameter for high frequency $(1500$ to $6000 \mathrm{~Hz})$ and two-microphone with a digital frequency to measure and analysis accident sound absorption coefficient.

Fig. 2: Polymer foam structures (a) polymer foam composite with diameter $28 \mathrm{~mm}$, (b) polymer composite with diameter $100 \mathrm{~mm}$.
Polymer foam were prepared in a cylindrical shape as refer in Figure 2 to fit in the sample holder of large tube and a small tube in acoustic tests.

\subsection{Scanning Electron Microscopy (SEM) of PU compo-} sites

Cellular structure images of polymer foams and its composite were analysis by using SEM of Hitachi operates at $10 \mathrm{kV}$ at $50 \mu \mathrm{m}$ magnifier under high vacuum. Figure 3 shows the SEM instrument. The polymer foams and its composites sample was prepared in $5 \mathrm{~mm} \times 5 \mathrm{~mm}$ with $10 \mathrm{~mm}$ thickness in order to fit in the sample holder of SEM. The sample prepared was attached on the holder using small size double carbon tape.

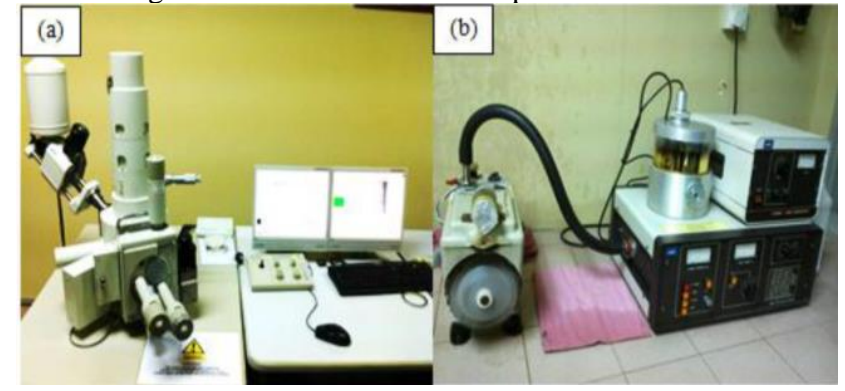

Fig. 3: The Scanning Electron Microscopy (SEM) instrument; (a): SEM of Hitachi; (b): Auto Fine Coater Machine.

\subsection{Accelerated weathering tests of $\mathrm{PU}$ and FC}

Ultra violet (UV) FC were conducted by using UV light in UV Lamp Test Chamber Model HD-703 (Haida International Equipment Co., LTD) (Figure 4). The UV Accelerated Weatherometer is used to reduce time and analysis the specimens on ultraviolet light exposure as the device can simulate the same actual exposure of the outside sunlight in the region of ultraviolet. The UV Accelerated Weathering test, which was conducted according to ASTM D 4587, was a standard practice for fluorescent UV-condensation exposure.

Figure 4 shows the working principle of the ultraviolet accelerated weathering tester. The controller use to measure the accurate quantity of irradiance expose in the chamber. The controller also control the power supply to adjust the current to the lamps to maintain the set point. During the ultra-violate cycle, light from fluorescent lamp will control by sensor to transmitted data [3]. UV Weathering Test Chamber use to simulate UV light but can short time to test the material in UV exposure. The temperature was set up to $50{ }^{\circ} \mathrm{C}$ to simulate a harsh environmental weather condition. In this measurement, the important precaution was to maintain the humidity and moisture content during the testing with controlled volume of distilled water inside the machine. In the accelerated weathering test, the specimens were placed on a rack holder in the UV-Weathering chamber at $50{ }^{\circ} \mathrm{C}$ with different exposure time under ultraviolet light at 2000, 4000, 6000, 8000 and 10000 hours. The UV exposure times of flexible polymer foam are tabulated in Table 2 .

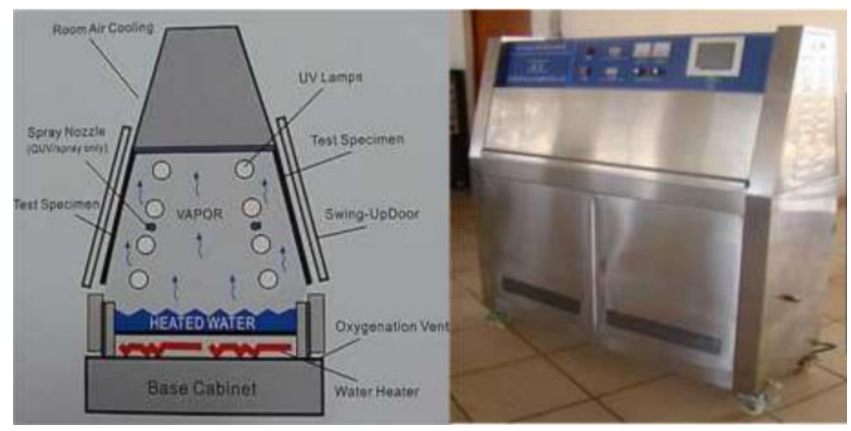

Fig. 4: UV-weathering chamber for sunlight simulation 


\section{Results and Discussion}

\subsection{Sound Absorption of polymer foam and its compo- site}

Sound absorption test has to be performed as it is a test to investigate the ability of certain material to absorb sound. Samples were prepared based on different wood fiber composition and thickness. Figure 6 shows the SAC for PP.
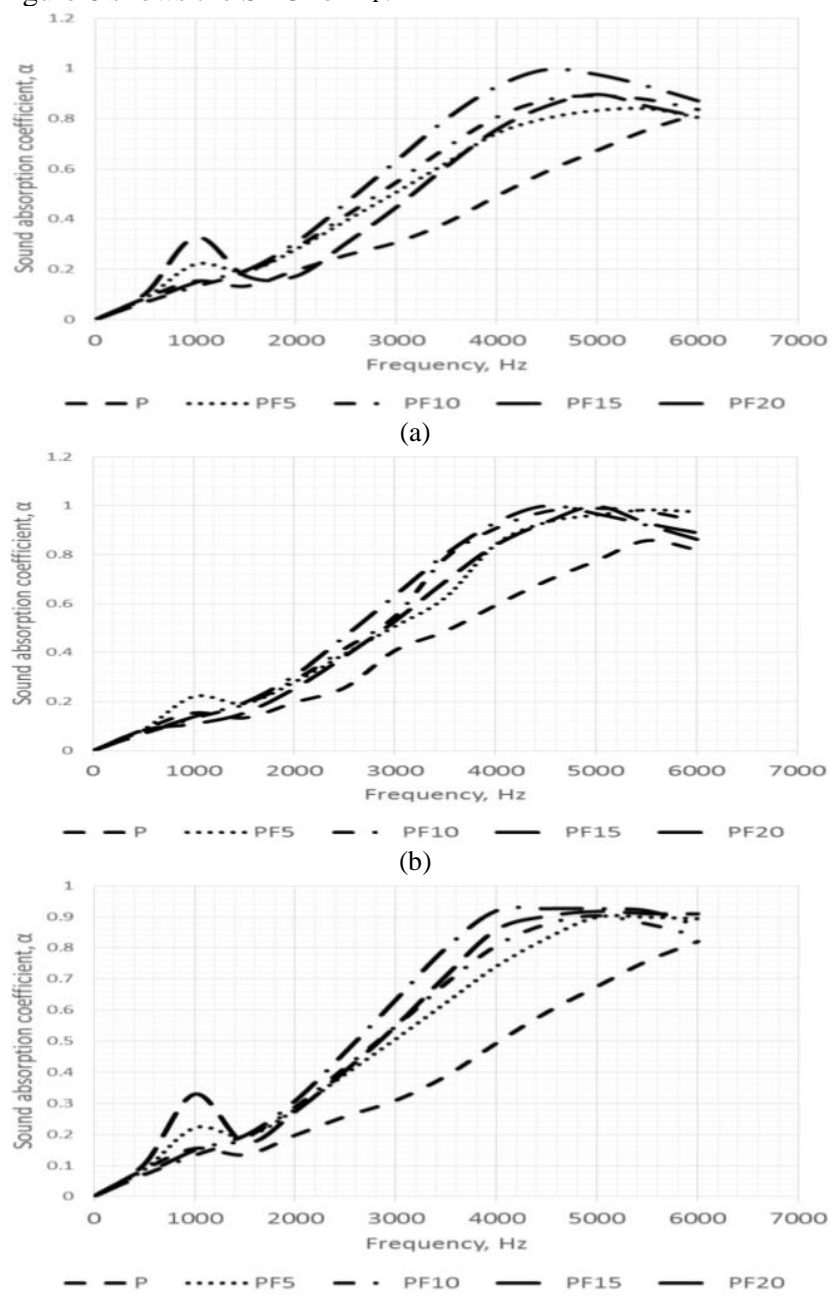

(c)

Fig. 6: $\mathrm{SAC}$ for: (a) $\mathrm{P}, \mathrm{P}_{\mathrm{P} 5} 10, \mathrm{P}_{\mathrm{P} 10} 10, \mathrm{P}_{\mathrm{P} 15} 10$ and $\mathrm{P}_{\mathrm{P} 20} 10$; (b) $\mathrm{P}, \mathrm{P}_{\mathrm{P} 5} 20$, $\mathrm{P}_{\mathrm{P} 10} 20, \mathrm{P}_{\mathrm{P} 15} 20$ and $\mathrm{P}_{\mathrm{P} 20} 20$ (c) $\mathrm{P}, \mathrm{P}_{\mathrm{P} 5} 30, \mathrm{P}_{\mathrm{P} 10} 30, \mathrm{P}_{\mathrm{P} 15} 30$ and $\mathrm{P}_{\mathrm{P} 20} 30$

Referring to Figure 6 (a), the SAC for FC is increasing as the increasing of the percentage filler loading for $\mathrm{P}_{\mathrm{P}} 10$. The highest SAC $(\alpha)$ value is 0.997 at $4862 \mathrm{~Hz}$ for Pp2010, followed by SAC $(\alpha)$ value is 0.897 at $5102 \mathrm{~Hz}$ for $\mathrm{P}_{\mathrm{P} 15} 10$, followed by 0.892 at frequency of $5009 \mathrm{~Hz}$ and 0.839 at $5550 \mathrm{~Hz}$ for Pp1010 and Pp510 respectively. Above all, $\mathrm{PU}$ acts as references for all $\mathrm{FC}$ samples. Referring to Figure 6 (b), the SAC for FC is increasing as the increasing of the percentage filler loading for P 20 . The highest SAC $(\alpha)$ value is 0.927 at $4662 \mathrm{~Hz}$ for PP2020, followed by SAC $(\alpha)$ value is 0.917 at frequency $5462 \mathrm{~Hz}$, for 0.903 at frequency of $5309 \mathrm{~Hz}$ and 0.899 at $5450 \mathrm{~Hz}$ for $\mathrm{P}_{\mathrm{P} 15} 20, \mathrm{P}_{\mathrm{P} 10} 20$ and $\mathrm{P}_{\mathrm{P} 5} 20 \mathrm{re}-$ spectively.

While referring to Figure 6 (c) for $\mathrm{MM}<212 \mu \mathrm{m}$, the highest SAC is $P_{P 20} 30$ with value 0.998 at frequency $4709 \mathrm{~Hz}$, followed by SAC $(\alpha)$ value is 0.997 at $5162 \mathrm{~Hz}$ for Pp1530. There is no significant change for $\mathrm{P}_{\mathrm{P} 1030}$ with SAC value 0.989 at frequency $5402 \mathrm{~Hz}$ compared to P $\mathrm{P} 530$, which has the lowest SAC value 0.982 with the highest frequency value $5415 \mathrm{~Hz}$.
The $\alpha$ of EP increases at frequency absorption level below then $1000 \mathrm{~Hz}$ and the higher sound absorption coefficient around 5000 hz.

On the other hand, the sound absorption of FC for all percentage filler loadings reduced with the increasing of pore size by referring to Figure 4.6 to Figure 4.8). The pore size will affected on sound absorption coefficient when occurring friction between inner cell wall and air, it will give higher number of converted energy. This also can be explained when the path longer, more the reflection and refraction in inner cell wall, that will cause the more energy absorption so the value of absorption coefficient greater.

Others, the Figure 6 (a)-(c) show the effected of thickness. The increasing thickness of material the increasing number of sound absorption on low frequency influence at higher wavelength sound [6-8].

The increase thickness of specimen, the larger number resistively of a material, the higher is its dissipation energy. [9-13].The thickness play important roles due to effective porous material in wavelength attend to appropriate wavelength [9-13].Sound absorbing materials absorb more energy when energy striking them and efficient in control energy most of the sound energy striking them and making them very useful for the control of noise. The increasing thickness will help and improved the resistively to specimen absorption material and gives increase performance to acoustic foam [14-17].The SAC increases when increasing in vibration, friction and viscosity of air that cause converted energy from sound energy to thermal energy, in whether commercial foam or foam based from cooking oil [18].

\subsection{Sound absorption of UV irradiation exposures of FC and PU}

As refer to Figure 7, the SAC value for PU sample shows significant decreases. However, the SAC curve was observed shifted towards higher frequency level after 1000 hrs of UV light exposures.

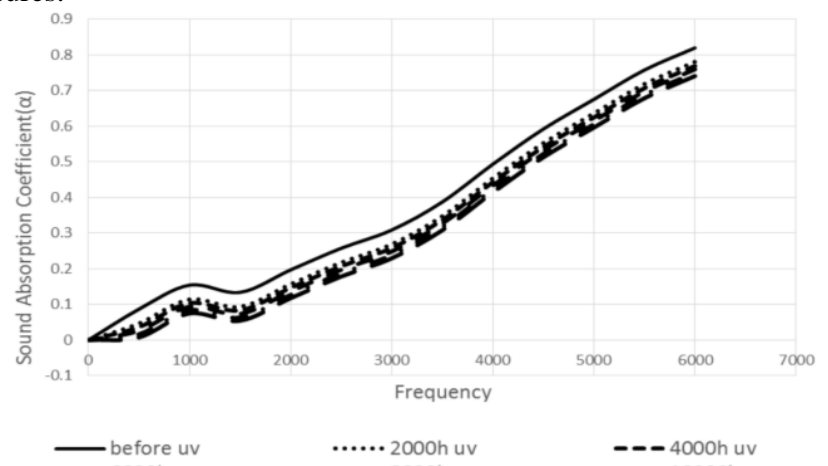

Fig. 7: SAC for P after UV irradiation exposures from 0 to $10000 \mathrm{hrs}$

The sound absorption property of PU and FC with UV exposure was analyzed based on Figure 7. The SAC values for PU shows significant changes after being exposed to UV light for $1000 \mathrm{hrs}$ compared to FC. The PU foam become less ductile after UV exposure. The duration of UV exposure at $2000 \mathrm{hrs}, 4000 \mathrm{hrs}, 6000 \mathrm{hrs}$, $8000 \mathrm{hrs}$ and $10000 \mathrm{hrs}$ for PU foam can cause the polymer breakdown and reduction of strength [19].

Referring to Figure 8, the graph shows the SAC pattern after UV irradiation exposures. It represents the PP30-FC. All samples were exposed from 0 to 10000 hrs under UV fluorescent light. 


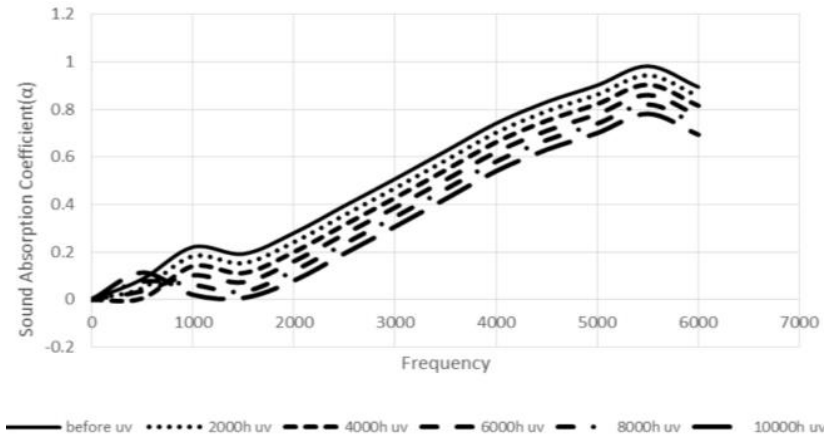

(a)

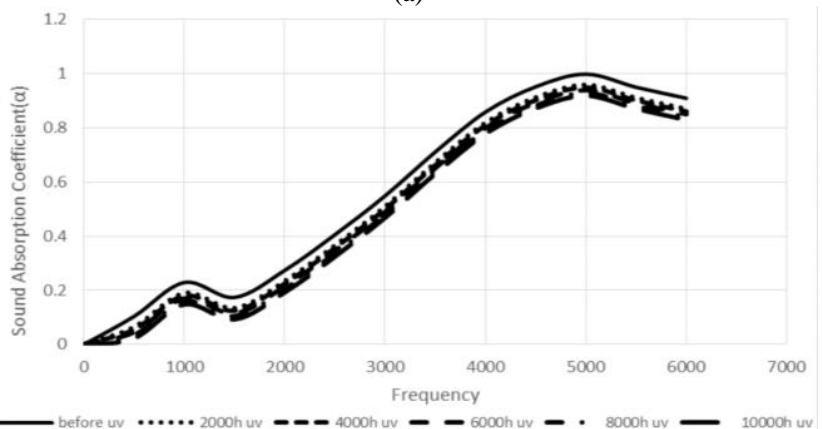

(b)

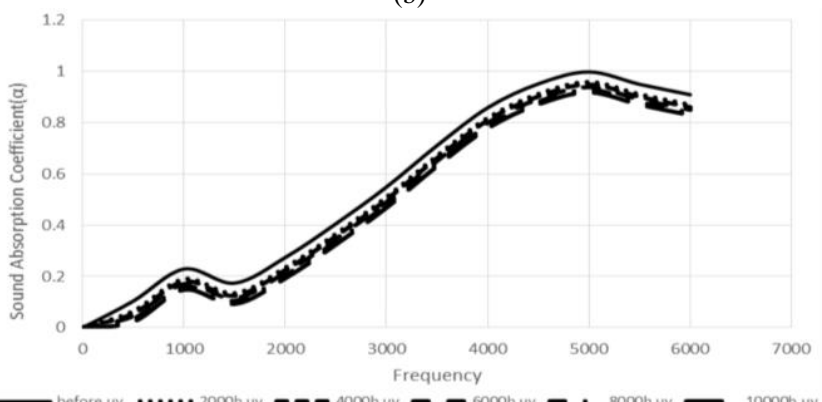

(c)

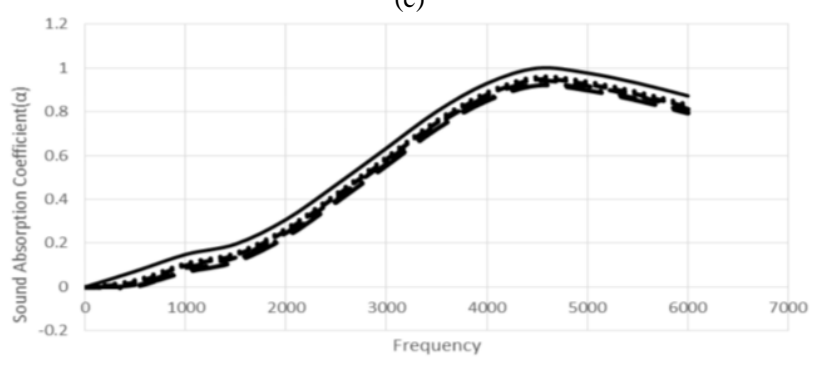

(d)

Fig. 8: (a): $\mathrm{SAC}$ for $\mathrm{P}_{\mathrm{P} 5} 30-\mathrm{FC}$ after UV irradiation exposures from 010000 hrs; (b): $\mathrm{SAC}$ for $\mathrm{P}_{\mathrm{P} 10} 30-\mathrm{FC}$ after UV irradiation exposures from 0 10000 hrs; (c): $\mathrm{SAC}$ for $\mathrm{P}_{\mathrm{P} 15} 30$-FC after UV irradiation exposures from 0 $10000 \mathrm{hrs}$; (d): $\mathrm{SAC}$ for $\mathrm{P}_{\mathrm{P} 20} 30-\mathrm{FC}$ after UV irradiation exposures from 0$10000 \mathrm{hrs}$

Referring to Pp2030, Figure 8 (a)-(d) show the changes of SAC value pattern after 10000 hrs UV exposures, shows almost unchanged in SAC value even though has been exposes up to 10000 hrs but the curve has slightly shifted to higher frequency level. However, as compared to percentages loading wood-FC, the $\mathrm{P}_{\mathrm{P}} 30$ the values were observed decreased percentages loading decrease SAC with the increasing of exposure time.

Above all, the FC samples were shifted towards higher frequency level as it being exposes to UV light, this phenomenon may be due to the increasing in pore size after 10000 hours exposures which resulting decreases of SAC value and band tend to shift to the higher frequency level. This phenomenon proved that deformation of foam can give impression that the product has physically degraded [20-23].
Concludes that the UV exposures for both wood FC has high durability against the UV exposures compared to PU. Some cases, the samples shows only small decreases in SAC value and slightly shifted to higher frequency absorption level. When compare the condition of the wood, the treated wood FC shows better absorption and also better resistance to UV light as the presences of acid in FC samples give strength between wood-matrix even the samples were exposed to UV light up to $10000 \mathrm{hrs}$. It is generally give small impact on the size of foam physically. This can be proved that wood filler with both conditions has high potential for soundproof applications.

\subsection{Foam Composite Production and Physical Proper- ties of Foam before and After UV Exposures}

The effects of weathering on foam yellowing performance have been observed. Figure 9 shows the foam unexposed and exposed under UV light. The polymer surface showing colour turn to yellowing results from an oxidation reaction.

After exposing 10000 hours to fluorescence lamp, results indicated that PU was the most yellow after exposed to UV light exposure compared to FC. Increasing times of UV exposures will enhance the yellowing performance thus resulting decreases of polymer lifetime. This resulting aromatic amine in polymer foam will oxidize when exposed to UV light and oxygen then produce Quinone. Quinones are yellow. They impart an increasing yellow due to the foam as oxidation proceeds over time [24-28]. The color change of FC does not show foam degradation. The produce of yellowing of foam is minor side and does not affect the quality of sample. The polymer foam is exposed to UV light for 10000 hours to see the ability of foam composites in resist the

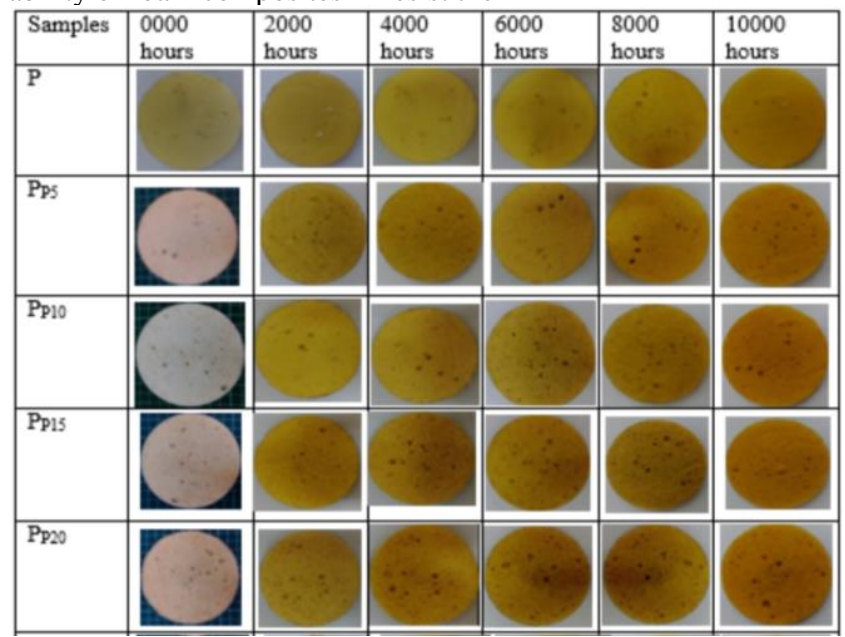

Fig. 9: Yellowing Performance after UV light exposures

\subsection{Foam Morphology}

Figure 10 shows the surface morphology of the epoxy (P) produced in this study. The SEM observations show the unnoticeable change on the surface for PU and both type and sizes of wood filler. In this study, SEM micrograph to observe surfaces prolonged being exposed to UV light and without coating were exposed to UV light for 10000 hours. This is to determine the properties of indicated by color, change, sunburn, crack growth, dirt, and deposition. It is necessary to prepare to determine their stability towards to resist aging from UV light [29]. 


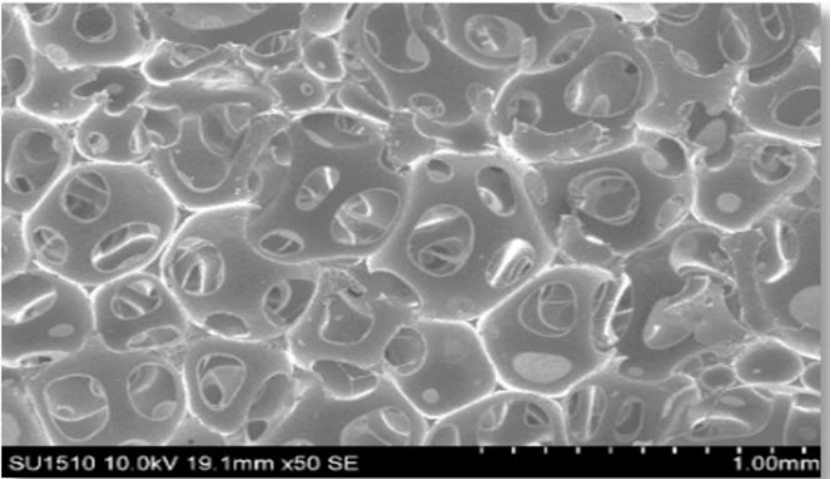

Fig. 10: SEM micrograph for PU foam based on epoxy $(P)$

In Figure 10, the polyol was compounded in polymer foam shows even pore structure, this might be due to better the polymer foam based from epoxy that commonly used for production of foam Polymer foam based from epoxy gives even pore size of the foam, whereby the optimum pore size can give increases the absorption coefficient at every stage of frequency level. In $[6,33]$ mentioned that the thickness and size of pore will influence the number value of sound absorption. When the thickness increase thickness, increase resistively, larger number dissipation and increase sound absorption. The interconnected pore of these polymer porous materials was another important factor to control the acoustic property. Figure 10 showed the polymer foam contains variable pore size [30].

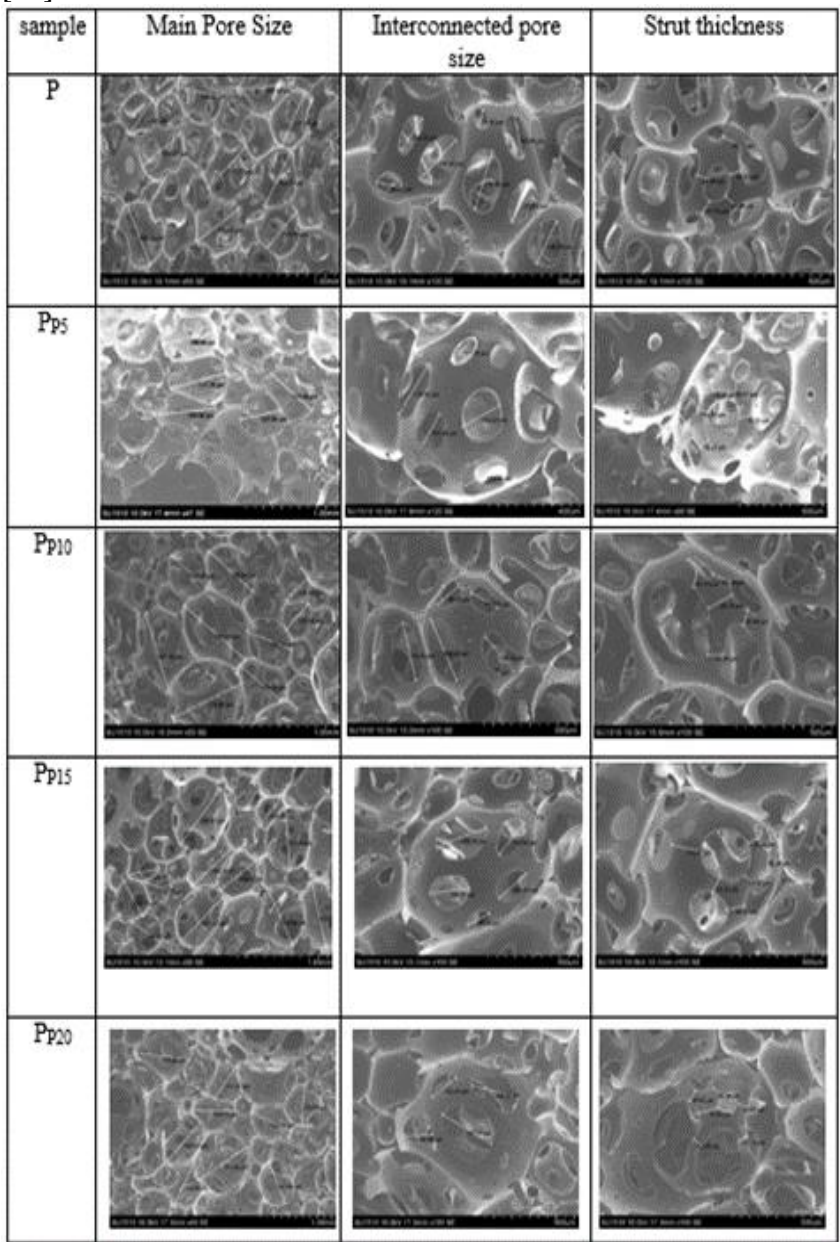

Fig. 11: SEM for P-FC before UV Irradiation exposures 10000 hours

Based on Figure 11, the P-FC was observed have uniform structures. According to $[6,33]$, the size of pores and its number influence in sound absorption property because when the sound pass through the sound absorbing material, sound wave dissipated by friction where the sound wave has to enter the porous material in order for the sound to be absorbed. This means that the porosity of the samples should have enough pores for sound absorption to take place where the sound will then pass through the porous area and damped itself. Table 2 shows the diameter for $\mathrm{P}$ foams average size is $385 \mu \mathrm{m}$. While, Table 3 show average pore size for $\mathrm{P}_{\mathrm{P}}$ from range 386 to $305 \mu \mathrm{m}$.

Table 2(a): Average main pore size $(\mu \mathrm{m})$ of $\mathrm{P}$ foam

\begin{tabular}{|c|c|c|c|c|c|c|}
\hline Foam Samples & 1 & 2 & 3 & 4 & 5 & Average Size \\
\hline P & 386 & 394 & 380 & 400 & 365 & 385 \\
\hline
\end{tabular}

Table 2(b): Average interconnected pore size $(\mu \mathrm{m})$ of $P$ foam

\begin{tabular}{|c|c|c|c|c|c|c|}
\hline Foam Samples & 1 & 2 & 3 & 4 & 5 & Average Size \\
\hline P & 220 & 165 & 115 & 132 & 140 & 154 \\
\hline
\end{tabular}

Table 2: (c) Average struts thickness $(\mu \mathrm{m})$ of $P$ foam

\begin{tabular}{|c|c|c|c|c|c|c|}
\hline Foam Samples & 1 & 2 & 3 & 4 & 5 & Average Size \\
\hline P & 105 & 100 & 130 & 104 & 101 & 108 \\
\hline
\end{tabular}

Table 3(a): Average pore main pore size $(\mu \mathrm{m})$ of $\mathrm{P}_{\mathrm{P}}$

\begin{tabular}{|c|c|c|c|c|c|c|}
\hline Foam Samples & 1 & 2 & 3 & 4 & 5 & Average Size \\
\hline $\mathrm{P}_{\mathrm{P} 5}$ & 388 & 387 & 382 & 375 & 399 & 386 \\
\hline $\mathrm{P}_{\mathrm{P} 10}$ & 368 & 329 & 374 & 380 & 391 & 362 \\
\hline $\mathrm{P}_{\mathrm{P} 15}$ & 245 & 345 & 332 & 371 & 252 & 309 \\
\hline $\mathrm{P}_{\mathrm{P} 20}$ & 302 & 299 & 255 & 320 & 349 & 305 \\
\hline
\end{tabular}

Table 3(b): Average interconnected pore size $(\mu \mathrm{m})$ of $\mathrm{P}_{\mathrm{P}}$

\begin{tabular}{|c|c|c|c|c|c|c|}
\hline Foam Samples & 1 & 2 & 3 & 4 & 5 & Average Size \\
\hline $\mathrm{P}_{\mathrm{P} 5}$ & 176 & 101 & 140 & 155 & 128 & 140 \\
\hline $\mathrm{P}_{\mathrm{P} 10}$ & 173 & 200 & 108 & 101 & 138 & 136 \\
\hline $\mathrm{P}_{\mathrm{P} 15}$ & 167 & 143 & 150 & 157 & 151 & 130 \\
\hline $\mathrm{P}_{\mathrm{P} 20}$ & 102 & 197 & 106 & 166 & 176 & 119 \\
\hline
\end{tabular}

Table 3(c): Average struts thickness size $(\mu \mathrm{m})$ of $\mathrm{P}_{\mathrm{P}}$

\begin{tabular}{|c|c|c|c|c|c|c|}
\hline Foam Samples & 1 & 2 & 3 & 4 & 5 & Average Size \\
\hline $\mathrm{P}_{\mathrm{P} 5}$ & 120 & 113 & 148 & 198 & 81 & 132 \\
\hline $\mathrm{P}_{\mathrm{P} 10}$ & 119 & 167 & 139 & 153 & 91 & 134 \\
\hline $\mathrm{P}_{\mathrm{P} 15}$ & 111 & 189 & 156 & 146 & 108 & 142 \\
\hline $\mathrm{P}_{\mathrm{P} 20}$ & 124 & 174 & 137 & 146 & 144 & 145 \\
\hline
\end{tabular}

As referring to the Table 2 to Table 3, all the fabricated foams for $\mathrm{P}-\mathrm{FC}$, the cellular structures were found smaller which give the better sound absorption with SAC value above 0.950 at medium frequency (2000 to $4000 \mathrm{~Hz}$ ) compared to large cellular structures value 0.90 at range at higher frequency absorption level (3500 to $6000 \mathrm{~Hz})$. In [12, 21, 31] has studied that the pore size give influence in sound absorption when the number of energy converted from sound to thermal which the smaller pore give more collision on the inner cell wall to long path reflection and refraction and more sound absorption.

In $[32,38]$ have proved that by adding filler in flexible PU foam will decrease the cell sizes of foam composites. This developed may be attributed to the viscosity generate during the filler-PU blend together. The higher viscosity tends to retard the cell growth and thus leading to smaller cell sizes formation of the FC.

Furthermore, Similar with change of size of pore, for strut diameter, Table 2 to Table 3, shows that the size of struts diameter for FC was observed almost unchanged. In [35] has studied that the influence of struts size. After the fabrication process of PU, the strut structure connected pore to each other and elimination of cellular structure of PU. The void of cell walls observed in PU and its composite, as shown in Table 2 to Table 3, the size of struts decreased with increasing of filler loading. Meanwhile, samples show dense surface area with reduction of cell sizes. Size of strut is important factor to give wave resist and get dampened in the pore [36]. In [37] have proved that by adding filler in flexible PU foam will decrease the cell sizes of foam composites. This proves that the presence of the fillers was responsible for cell disturbance during foam production stage. 


\subsection{Foam Morphology of PU and wood-FC after UV Irradiation exposures}

Polyurethanes are subject to degradation when exposed to ultraviolet light from natural and/or artificial sources. Degradation results in discoloration and/or loss of physical properties. Figure 12 and Figure 13 show the cellular structure for foams after UV exposures. Figure 13 shows the pore for Pp-FC after $10000 \mathrm{hrs}$ UV exposure for $5 \mathrm{wt} \%, 10 \mathrm{wt} \%, 15 \mathrm{wt} \%$ and $20 \mathrm{wt} \%$ percentage filler loading.

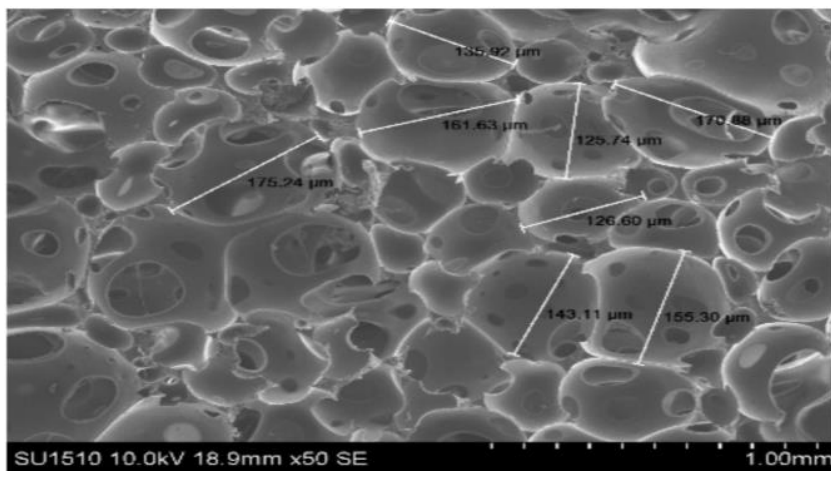

Fig. 12: SEM for $P$

Referring to Figure 12, the cellular structures for PU were increased after $10000 \mathrm{hrs}$ UV exposure compare with the unexposed FC cellular structure. The increased of pores cell structure size after UV exposure has decreasing the absorption frequencies at higher level.

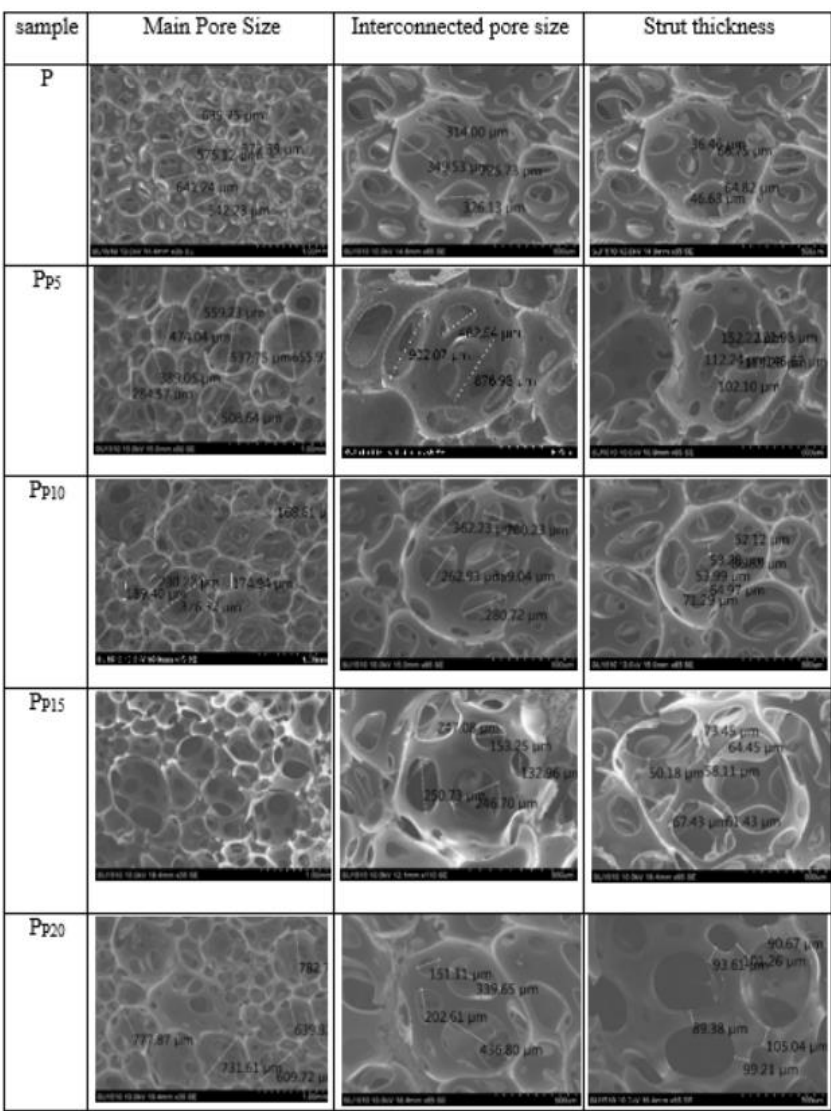

Fig. 13: SEM for P-FC after UV Irradiation exposures 10000 hours

Based on Figure 13, the FC were found to have main pore, interconnected and struts thickness structures. It showed the sample structures of P-FC. The P FC was observed have uniform structures compared. Table 4 shows the diameter for $\mathrm{P}$ foams average size of $589 \mu \mathrm{m}$, while Table 5 shows average pore size for $\mathrm{P}_{\mathrm{P}}$ from range 577 to $499 \mu \mathrm{m}$.

Table 4(a): Average main pore size of $\mathrm{P}$ foam

\begin{tabular}{c|c|c|c|c|c|c}
\hline Foam samples & 1 & 2 & 3 & 4 & 5 & Average size \\
\hline P & 663 & 569 & 670 & 507 & 533 & 385
\end{tabular}

Table 4(b): Average interconnected pore size of $\mathrm{P}$ foam

\begin{tabular}{cccc|c|c|c|c}
\hline Foam samples & 1 & 2 & 3 & 4 & 5 & Average size \\
\hline P & 263 & 225 & 301 & 298 & 289 & 385
\end{tabular}

Table 4(c): Average struts thickness of $P$ foam

\begin{tabular}{c|c|c|c|c|c|c}
\hline Foam samples & 1 & 2 & 3 & 4 & 5 & Average size \\
\hline P & 110 & 83 & 106 & 113 & 78 & 385 \\
\hline
\end{tabular}

Table 5(a): Average pore main pore size of $\mathrm{P}_{\mathrm{P}}$

\begin{tabular}{c|c|c|c|c|c|c}
\hline Foam samples & 1 & 2 & 3 & 4 & 5 & Average size \\
\hline $\mathrm{P}_{\mathrm{P} 5}$ & 289 & 242 & 328 & 235 & 271 & 273 \\
\hline $\mathrm{P}_{\mathrm{P} 10}$ & 142 & 252 & 223 & 285 & 273 & 255 \\
\hline $\mathrm{P}_{\mathrm{P} 15}$ & 204 & 173 & 252 & 228 & 161 & 239 \\
\hline $\mathrm{P}_{\mathrm{P} 20}$ & 144 & 199 & 195 & 232 & 200 & 234 \\
\hline
\end{tabular}

Table 5(b): Average interconnected pore size of $\mathrm{P}_{\mathrm{P}}$

\begin{tabular}{c|c|c|c|c|c|c}
\hline Foam samples & 1 & 2 & 3 & 4 & 5 & Average size \\
\hline $\mathrm{P}_{\mathrm{P} 5}$ & 90 & 72 & 106 & 134 & 128 & 106 \\
\hline $\mathrm{P}_{\mathrm{P} 10}$ & 85 & 109 & 100 & 82 & 154 & 106 \\
\hline $\mathrm{P}_{\mathrm{P} 15}$ & 96 & 104 & 114 & 88 & 142 & 109 \\
\hline $\mathrm{P}_{\mathrm{P} 20}$ & 143 & 120 & 107 & 113 & 98 & 116
\end{tabular}

The pores were observed increase in diameter when exposed to light up to $10000 \mathrm{hrs}$ as refer to Table 4 to Table 5. Conversely to PU results, Figure 13 shows the size of structures of FC upon UV exposures was observed unnoticeable changes in physically but increased in pores size for all the samples. This also proved that wood-FC structure have a minor impact on the physical properties of the foam during the aging of polyurethane foams, photodegradation processes occur that strongly influence the physical properties of the materials [39]. This Meranti Merah wood-FC after UV irradiation exposures shows high resistance to UV irradiation exposure.

Proved by [40], once the efficient flow coefficients of sample and inner wall air are determined, they can be used in the transient efficient equation to predict the change of the gas efficiency with time in foams. The effective foam diffusion coefficient can be determined by lengthy foam-permeability measurements (which give little physical insight into foam aging behavior) or can be evaluated based on the knowledge of the foam geometry and permeability of the solid polymer cell walls. The important geometry parameters are: cell wall thickness, cell size, arrangement, elongation and percent of open cells.

\section{Conclusion}

The results obtained from the tests concluded that the objectives of the study is successfully done. Data that had been analyzed show that mechanical properties of polymer foam composite is affected by different percentage loading of wood fiber filler and polymer foam composite with different loading filler of wood with different thickness. Mechanical properties obtained from physical testing are sound absorption of polymer foam composite will be determined experimental by using impedance tube test., using SEM to identify structure pore of polymer foam and density test. The data that obtained show that the sound absorption coefficient level of polymer foam composite with different percentage loading of wood fiber filler and different thickness give impact to the result of mechanical properties of polymer foam composite. Wood filler show the higher value of percentage loading and different loading filler of wood with different thickness, the higher of sound absorption coefficient. From this study the result show the higher $(\alpha)$ is the thickness of $30 \mathrm{~mm}$ and the foam percentage $20 \%$ 
is 0.9989. From SEM, the structure of wood filler and their effected are detected in the foam.

As to conclude the best sample material from this study it is from flakes particles size, that mostly get the higher value of percentage wood fiber filler loading and the higher thickness of foams to produce the perfect material of sound absorption coefficient.

Meranti Merah wood can be adding as a filler in sound absorption material and the effectiveness of samples was determined by the condition and the percentage filler added. Thus, FC have been developed with $5 \%, 10 \%, 15 \%$ and $20 \%$ filler loading of MM gives different result in sound absorption coefficient at different frequency level. The wood FC gives variety value of SAC which approaching to 1 . The morphology study indicates that FC has variety in size of the cellular structure compared to PU.

The yellowing is caused by an oxidation reaction in the surface of the polymer foam. Since it is the polymer itself which is being oxidized, the yellow color cannot be extracted and the foam will ultimately degrade. In this study, the UV exposures did not give high impact to the FC as the result shows the absorption band only slightly shifted toward higher frequency level. This has proved that the Meranti Merah is highly resistance to UV light and suitable for sound-proofing blanket and curtain systems for outdoor sound applications.

\section{Acknowledgment}

The author would like to thank the supervisor and all who have contributed in making this research a success. The author would like to thank Universiti Tun Hussein Onn Malaysia (UTHM), University Technology Petronas (UTP) under IGSP U678 and A136.

\section{References}

[1] Rus, A. Z. M., Azahari, M. S. M., Zaliran, M. T \& Kormin, S. (2017). Hybrid waste filler filled bio-polymer foam composites for sound absorbent materials. AIP Conference Proceedings, 1877(1), $1-8$.

[2] Hassan, N. N. M., \& Rus A. Z. M. (2016). Thermal and activation energy of renewable polymer after UV irradiation. ARPN Journal of Engineering and Applied Sciences, 11(3), 1510-1514.

[3] Rus, A. M. (2010). Polymers from renewable materials. Science Progress, 93(3), 285-300.

[4] Rus A. Z., Kemp T. J., \& Clark A. J. (2009). Degradation studies of polyurethanes based on vegetable oils. Part 2. Thermal degradation and materials properties. Progress in Reaction Kinetics and Mechanism, 34(1), 1-41.

[5] Rus A. Z. M., Kemp T. J., \& Clark A. J. (2008). Degradation studies of polyurethanes based on vegetable oils. Part 1 . Photodegradation, Progress in Reaction Kinetics and Mechanism, 33(4), 363-391.

[6] Seddeq, H. S. (2009). Factors influencing acoustic performance of sound absorptive materials. Australian Journal of Basic and Applied Sciences, 3(4), 4610-4617.

[7] Juan, V. C. R, Lerma, H. C. C, Fernando, H. S, \& José, M. C. U. (2013). Degradation of polyurethanes for cardiovascular applications. In R. Pignatello (Ed.), Advances in Biomaterials Science and Biomedical Applications. London: IntechOpen, pp. 5182.

[8] Chen, B., Zhao, J., \& Rao, Z. (2016). Thermal conductivity of energy conversion and storage composite materials packing with short fiber fillers and artificial size cylinder fillers. Applied Thermal Engineering, 103, 1196-1204.

[9] Francisco, S., \& Jaime, P. (2004). Guidelines for the acoustic design of absorptive devices. Noise and Vibration Worldwide, 35(1), 12-21.

[10] Zhao, T., Yang, M., Wu, H., Guo, S., Sun, X., \& Liang, W. (2015). Preparation of a new foam/film structure poly (ethylene-co-octene) foam materials and its sound absorption properties. Materials Letters, 139, 275-278.

[11] Harhash, M., Sokolova, O., Carradó, A., \& Palkowski, H. (2014) Mechanical propertiesand forming behaviour of laminated steel/polymer sandwich systems withlocal inlays-Part 1. Compos. Struct., 118, 112-120.

[12] Wang, F., Wang, L. C., Wu, J. G., \& You, X. H. (2007). Sound absorption property of open-pore aluminum foams. Research and Development, February 2007, 31-33.

[13] Connolly, M., King, J. P., Shidaker, T. A., \& Duncan, A. C. (2006) Characterization of pultruded polyurethane composites: Environmental exposure and component assembly testing. Proceedings of the Composites, pp. 18-20.

[14] Coates, M., \& Kierzkowski, M. (2002). Acoustic textiles--lighter, thinner and more sound-absorbent. Tech Text Int, 11(7), 15.

[15] Chen, B., Zhao, J., \& Rao, Z. (2016). Thermal conductivity of energy conversion and storage composite materials packing with short fiber fillers and artificial size cylinder fillers. Applied Thermal Engineering, 103, 1196-1204

[16] Zhao, T., Yang, M., Wu, H., Guo, S., Sun, X., \& Liang, W. (2015). Preparation of a new foam/film structure poly (ethylene-co-octene) foam materials and its sound absorption properties. Materials Letters, 139, 275-278.

[17] Harhash, M., Sokolova, O., Carradó, A., Palkowski, H., 2014. Mechanical propertiesand forming behaviour of laminated steel/polymer sandwich systems withlocal inlays-Part 1. Compos. Struct., 118, 112-120.

[18] Rus, A. Z. M., Normunira, N. M., \& Rahim, R. A. (2014). Influence of multilayer textile biopolymer foam doped with titanium dioxide for sound absorption materials. Key Engineering Materials, 594, 750-754.

[19] Azahari, M. S. M., Rus, A. Z. M., Zaliran, M. T., \& Kormin, S. (2017, August). Improving sound absorption property of polyurethane foams doped with natural fiber. IOP Conference Series: Materials Science and Engineering, 226(1), 1-6.

[20] Valentine, C., Craig, T. A., \& Hager, S. L. (1993). Inhibition of the discoloration of polyurethane foam caused by ultraviolet light. Journal of cellular plastics, 29(6), 569-588.

[21] Wang, F., Wang, L. C., Wu, J. G., \& You, X. H. (2007). Sound absorption property of open-pore aluminum foams. Research and Development, February 2007, 31-33.

[22] Connolly, M., King, J. P., Shidaker, T. A., \& Duncan, A. C. (2006). Characterization of pultruded polyurethane composites: Environmental exposure and component assembly testing. Proceedings of Composites, pp. 18-20.

[23] Valentine, C., Craig, T. A., \& Hager, S. L. (1993). Inhibition of the discoloration of polyurethane foam caused by ultraviolet light. Journal of cellular plastics, 29(6), 569-588.

[24 Juan, V. C. R, Lerma, H. C. C, Fernando, H. S, \& José, M. C. U. (2013). Degradation of polyurethanes for cardiovascular applications. In R. Pignatello (Ed.), Advances in Biomaterials Science and Biomedical Applications. London: IntechOpen, pp. 5182

[25] Elleder, M., \& Borovanský, J. (2001). Autofluorescence of melanins induced by ultraviolet radiation and near ultraviolet light. A histochemical and biochemical study. Histochemical Journal, 33(5) 273-281.

[26] Tiuc, A. E., Vasile, O., Usca, A. D., Gabor, T., \& Vermesan, H. (2014). The analysis of factors that influence the sound absorption coefficient of porous materials. Romanian Journal of Acoustics and Vibration, 11(2), 105-108.

[27] Mathur, G., \& Fuller, C. (2016). Novel sound absorptive materials based on acoustic metamaterial principles. Proceedings of the $23 \mathrm{rd}$ Int. Congr. Sound Vib, pp. 1-8.

[28] Boubakri, A., Elleuch, K., Guermazi, N., \& Ayedi, H. F. (2009). Investigations on hygrothermal aging of thermoplastic polyurethane material. Materials and Design, 30(10), 3958-3965.

[29] Rus, A. Z. M., Mohid, S. R., Nurulsaidatulsyida, S., \& Marsi, N. (2013). Biopolymer doped with titanium dioxide superhydrophobic photocatalysis as self-clean coating for lightweight composite. Advances in Materials Science and Engineering, 2013, 1-9.

[30] Rus A. Z., Kemp T. J., \& Clark A. J. (2009). Degradation studies of polyurethanes based on vegetable oils. Part 2. Thermal degradation and materials properties. Progress in Reaction Kinetics and Mechanism, 34, 1, 1-41.

[31] Wang, F., Wang, L. C., Wu, J. G., \& You, X. H. (2007). Sound absorption property of open-pore aluminum foams. Research and Development, February 2007, 31-33.

[32] Verdejo, R., Stämpfli, R., Alvarez-Lainez, M., Mourad, S., Rodriguez-Perez, M. A., Brühwiler, P. A., \& Shaffer, M. (2009). Enhanced acoustic damping in flexible polyurethane foams filled with 
carbon nanotubes. Composites Science and Technology, 69(10), 1564-1569.

[33] Seddeq, H. S. (2009). Factors influencing acoustic performance of sound absorptive materials. Australian Journal of Basic and Applied Sciences, 3(4), 4610-4617.

[34] Wang, F., Wang, L. C., Wu, J. G., \& You, X. H. (2007). Sound absorption property of open-pore aluminum foams. Research and Development, February 2007, 31-33.

[35] Adnan, N. Q. A., Rus, M., \& Zafiah, A. (2013). Sound absorption of laminated biopolymer foam and epoxy foam. Key Engineering Materials, 595, 291-295.

[36] Allard, J. F. (2009). Propagation of sound in porous media: Modelling sound absorbing materials. John Wiley and Sons.

[37] Sung, G., Kim, S. K., Kim, J. W., \& Kim, J. H. (2016). Effect of isocyanate molecular structures in fabricating flexible polyurethane foams on sound absorption behavior. Polymer Testing, 53, 156-164.

[38] Verdejo, R., Stamfli, R., Alvarez-Lainez, M., Mourad, S., Rogriguez-Perez, M. A., \& Brühwiler, P. A. (2009). Enhanced acoustic damping in flexible polyurethane foams filled carbon nanotubes. Composite Science Technology, 69, 1564-9.

[39] Noble, P. S., Goode, B., Krouskop, T. A., \& Crisp, D. B. Aging of polyurethane foams. Journal of Rehabilitation Research and Development, 21(2), 31 -38.

[40] Ostrogorsky, A. G., Glicksman, L. R., \& Reitz, D. W. (1986) Aging of polyurethane foams. International Journal of Heat and Mass Transfer, 29(8), 1169-1176. 